\title{
Placental immune response to apple allergen in allergic mothers
}

\author{
Martina Abelius, Uta Enke, Frauke Varosi, Heike Hoyer, Ekkehard Schleussner, Maria \\ Jenmalm and Udo R. Markert
}

\section{Linköping University Post Print}

\section{Tweet}

N.B.: When citing this work, cite the original article.

Original Publication:

Martina Abelius, Uta Enke, Frauke Varosi, Heike Hoyer, Ekkehard Schleussner, Maria Jenmalm and Udo R. Markert, Placental immune response to apple allergen in allergic mothers, 2014, Journal of Reproductive Immunology, (106), 100-109.

http://dx.doi.org/10.1016/j.jri.2014.05.001

Copyright: Elsevier http://www.elsevier.com/

Postprint available at: Linköping University Electronic Press http://urn.kb.se/resolve?urn=urn:nbn:se:liu:diva-113184 


\section{Placental immune response to apple allergen in allergic mothers}

2

3

4 Martina Sandberg Abelius ${ }^{1,2,3,{ }^{*}, \text { Uta Enke }}{ }^{1,{ }^{*}}$, Frauke Varosi $^{1}$, Heike Hoyer ${ }^{4}$,

$5 \quad$ Ekkehard Schleussner ${ }^{1}$, Maria C Jenmalm ${ }^{2,3}$, Udo R Markert ${ }^{1}$

6

7 *Both authors contributed equally to this work

8

$9{ }^{1}$ Placenta Laboratory, Department of Obstetrics, University Hospital Jena, D-07740

10 Jena, Germany

112 Division of Pediatrics, Department of Clinical and Experimental Medicine, and

12 Clinical Research Centre, Faculty of Health Science, Linköping University, SE-581 85

13 Linköping, Sweden

$14{ }^{3}$ Unit of Autoimmunity and Immune Regulation, Division of Inflammation Medicine,

15 Department of Clinical and Experimental Medicine, Faculty of Health Science,

16 Linköping University, SE-581 85 Linköping, Sweden

$17{ }^{4}$ Centre for Clinical Studies, University Hospital Jena, D-07740 Jena, Germany 


\section{Correspondence:}

28 Prof. Dr. Udo R. Markert

29 Placenta Laboratory, Department of Obstetrics, University Hospital Jena, D-07740

30 Jena, Germany

31 Telephone: $+49-3641-933763$

32 Fax: $\quad+49-3641-93376$

33 Email: markert@med.uni-jena.de

34

35 Key Words: allergy, chemokines, ex vivo placenta perfusion, histamine, IL-6,

36 placenta, TNF 
38 Introduction: The immunological milieu in the placenta may be crucial for priming

39 the developing fetal immune system. Early dysbalances may promote establishment

40 of immune-mediated diseases in later life including allergies. The initial exposure to 41 allergens seems to occur in utero, but little is known about allergen induced placental 42 cytokine and chemokine release.

43 Objectives: The release of several cytokines and chemokines from placenta tissue 44 after exposure to mast cell degranulator compound $48 / 80$ or apple allergen in 45 placentas from allergic and healthy mothers should be analyzed. applied in a placenta perfusion model with two separate cotyledons simultaneously perfused with and without apple allergen (Mal d 1). Two control placentas were perfused with compound 48/80. In outflow, histamine was quantified spectrophotofluorometrically, IL-2, IL-4, IL-6, IL-10, TNF and IFN- $\gamma$ by a cytometric multiplex bead array and IL-13 and CXCL10, CXCL11, CCL17 and CCL22 with an in-house multiplex Luminex assay.

Results: Compound 48/80 induced a rapid release of histamine, CXCL10, CXCL11, CCL17 and CCL22, but not of the other factors. Apple allergen induced a timedependent release of IL-6 and TNF, but not of histamine, in placentas of women with apple allergy as compared to the unstimulated cotyledon. CCL17 levels were slightly increased after allergen stimulation in control placentas.

Conclusion: Allergens can induce placental cytokines and chemokines distinctly in allergic and healthy mothers. These mediators may affect the prenatal development of the immune system and modify the risk for diseases related to immune disorders in childhood such as allergies. 


\section{Introduction}

64 The prevalence of allergic diseases has increased during the last decades (Burr et al. 1989, Asher et al. 2006). Genetic factors are important for allergy development, but a time period of $30-40$ years is considered to be to short for human genetic composition to undergo such dramatic changes causing this increasing prevalence. As a consequence, a lot of attention has been drawn to the postnatal exposure to environmental factors associated with a westernized lifestyle. Exposure to environmental factors important for allergy development appears to be important very early in life, perhaps even before birth (Jenmalm and Bjorksten 1998). This concept was first developed in 1989, when D. J. P. Barker highlighted the possible link between events in utero and development of diseases in adult life, called "fetal programming of diseases" (Barker et al. 1989). Prenatal farm exposure reduces the risk of asthma symptoms, allergic rhinoconjunctivitis and eczema (Douwes et al. 2008) and maternal exposure to stables during pregnancy protects against allergic sensitization, whereas exposures later in life has limited or no effect at all (Ege et al. 2006, Lampi et al. 2011). The role for the gestational environment on the shaping or immune responses in the offspring and development of allergic diseases needs further investigation, however.

The initial exposure to allergens may occur in utero. House dust mite allergen has been detected in the amniotic fluid and in the fetal circulation, indicating a transamniotic and a transplacental transfer (Holloway et al. 2000). Dual perfusion experiments have shown a maternal-fetal passage of $\beta$-lactoglobulin, ovalbumin and birch pollen (Loibichler et al. 2002, Edelbauer et al. 2003, Edelbauer et al. 2004) but also an accumulation of allergen in the syncytiotrophoblast cell layer (Szepfalusi et al. 2006). Detectable allergen-specific T cell responses at birth, shown as a capability 
of cord blood mononuclear cells (CBMC:s) to produce cytokines in response to allergens, support the idea of intrauterine allergen exposure and priming of the fetal immune system (Kondo et al. 1998, van der Velden et al. 2001). On the other hand,

91 the neonatal CD4+ T cell population has shown a typical phenotype of recent thymic 92 emigrants, with receptors lacking the specificity of conventional T cells and may thus 93 be capable to interact with a multitude of antigens, i.e. allergens (Thornton et al. 94 2004).

95 Human term placenta consists of several cell populations including fibroblasts, 96 smooth muscle cells, endothelial cells, cyto- and syncytiotrophoblast cells and 97 immune cells such as macrophages, T cells and mast cells. Many of these cells are 98 able to produce cytokines and chemokines, but macrophages, endothelial cells and 99 trophoblast cells can be accounted for the major production (Steinborn et al. 1998, 100 Keelan et al. 1999). The chemokines function as attractants for leukocytes to the site 101 of inflammation and the regulation of leukocyte maturation (Pease and Williams 102 2006). The interleukin (IL)-4 and IL-13 induced chemokines CCL17 and CCL22 103 (Andrew et al. 1998, Nomura et al. 2002) bind to the CCR4 receptor expressed on 104 Th2 lymphocytes, mast cells, dendritic cells and natural killer T (NKT) lymphocytes 105 (Pease and Williams 2006). The interferon- $\gamma$ (IFN- $\gamma$ ) induced chemokines CXCL10 and CXCL11 (Luster and Ravetch 1987, Cole et al. 1998) attract CXCR3 receptor expressing Th1 lymphocytes, NKT and mast cells (Pease and Williams 2006). Although allergy is associated with increased allergen induced levels of IL-4, IL-5, IL13, CCL17 and CCL22 by peripheral mononuclear cells (PBMCs) (Imada et al. 1995, Till et al. 1997a, Till et al. 1997b, Sun et al. 2007), little is known about the allergen induced cytokine and chemokine production at the local level in the placenta.

Furthermore, allergen induced mast cell degranulation in the placenta has not been 
113 demonstrated. A pronounced placental Th2 shift in allergic mothers has been

114 suggested to explain the greater risk of maternal allergy as compared to paternal

115 allergy for development of allergic diseases in the offspring (Ruiz et al. 1992, Liu et 116 al. 2003). Furthermore, the higher cord blood (CB) IgE levels in children of allergic 117 mothers than children with paternal or no allergic history (Johnson et al. 1996, Liu et al. 2003) support a possible exaggerated placental Th2 phenotype among the 119 allergic women. Exposure to a strong Th2 milieu during fetal development could 120 generate long lasting effects in the offspring by modulation of their immune 121 responses, to an IgE favouring, Th2-like phenotype, possibly promoting allergy 122 development later in life.

123 The aim of the present study was to analyze the cytokines IL-2, IL-4, IL-6, IL-10, IL124 13, IFN- $y$, Tumor necrosis factor (TNF), the chemokines CXCL10, CXCL11, CCL17, 125 CCL22 and histamine release in placentas after stimulation with apple allergen or the 126 mast cell degranulating compound $48 / 80$ in relation to maternal allergic disease. 


\section{Subjects}

130 Four women with an oral allergy syndrome displaying allergic symptoms to apple and

1315 women without any allergic symptoms from the Jena area, region of Thuringia,

132 Germany, were included in the study. The following inclusion criteria were applied:

delivery after week 37 of pregnancy, a healthy appropriately grown newborn, absence of maternal chronic metabolic diseases, pharmacological therapy and pregnancy complications. In their anamneses, none of the allergic patients has reported systemic reactions, but only the classical local reactions as described for the oral allergy syndrome (Ortolani et al. 1988). The similar severity of described symptoms did not allow subdivision of the patients group. All study participants gave their written informed consent. The regional ethics committee of the Medical Faculty of Friedrich Schiller University Jena approved the study (No. 1038-02/03).

141 In advance to delivery, circulating allergen specific $\lg E$ antibodies to the major allergens of apple (Mal d 1) and birch (Bet v1; because of their cross-reactivity (Klinglmayr et al. 2009)) were measured in serum of the allergic women by using specific IgE tests (ImmunoCAP; Phadia, Freiburg, Germany) and a Phadia®250 system. If this was not practicable, a rapid immunographic allergy screening test (Auro Dex Visual-ENS test, including birch, other tree and grass pollen, and frequent animal allergens; Dexall, USA) was conducted in the delivery room. After delivery, results were confirmed by an ImmunoCAP test. Sensitisation to additional allergens did not lead to exclusion. Both of the rapid diagnosis allergy tests were also used to exclude allergic sensitisation in the anamnestically non-allergic women. The sensitivity and specificity of the Auro-Dex Visual-Ens has been assessed previously 152 (Pietsch 2006). 
153 Three of the four allergic women had in our laboratory a positive IgE test to apple or 154 birch (CAP class II-V) and the fourth patient showed a medical certificate for 155 confirmation of sensitisation to apple (CAP class II). CAP classes could not be used 156 for defining subgroups due to the limited availability of placentas from allergic 157 individuals. None of the non-allergic women were sensitised to the analysed 158 allergens.

\section{Isolation of apple allergen (Mal d 1)}

Mal d 1 was extracted from fresh apples in the same lab and by using the same protocol as previously published (Rudeschko et al. 1995a, Rudeschko et al. 1995b). The concentration has been determined as described previously (Vieths et al. 1994, Rudeschko et al. 1995b). Briefly, apples (Golden Delicious from a local store) were homogenised at $4^{\circ} \mathrm{C}$ in an extraction buffer containing phosphate-buffered saline (PBS; PAA, Pasching, Austria), Polyvinylpyrrolidon (Sigma-Aldrich, Steinheim, Germany), Ethylenediaminetetraacetic acid (EDTA; Roth, Karlsruhe, Germany), Diethyl-dithiocarbamate (Sigma-Aldrich), Benzamidinhydrochlorid (Sigma-Aldrich) and Phenylmethan-Sulfonyl-chlorid (Sigma-Aldrich), at pH 7.4 using a pH meter (FiveEasy; Mettler-Toledo, Gießen, Germany). The homogenised apples were filtered and dialysed two times against an EDTA - Diethyldithiocarbamate solution and 3 times against a Tris(hydroxymethyl)aminomethane (Tris; Sigma-Aldrich) buffer, pH 8.0. The extract was applied on a Q-Sepharose Fast Flow column (SigmaAldrich) and eluted by addition of Tris, $\mathrm{pH}$ 8.0. The total concentration of protein in the eluate was determined by a Bradford assay and the concentration of Mal $d 1$ with ELISA (Heinzelmann 2005). Mal d 1 was lyophilised and stored at $-20^{\circ} \mathrm{C}$. Two $\mathrm{kg}$ apples generated $13 \mathrm{mg}$ Mal d 1 . We have produced and used a total two lots of the 
above described allergen preparation and both have been used for perfusion of placentas of allergic and non-allergic mothers. The activity and stability of the so produced allergen has been reported in detail previously (Rudeschko et al. 1995a, Rudeschko et al. 1995b).

\section{One sided placenta perfusion}

184 Placentas were obtained after spontaneous delivery (Allergic women $n=3$, Non185 allergic women $n=1$ ) or cesarean section (Allergic women $n=1$, Non-allergic women $n=2$ groups have been merged. A single sided placenta perfusion system was developed which allows simultaneous separate and independent perfusion of two cotyledons of the same placenta. In all experiments one cotyledon has been perfused with apple allergen or compound $48 / 80$ and the other with control medium. To evaluate the placenta vitality and functionality in this system, we compared metabolic parameters in conditioned perfusion medium with those in dually (fetal and maternal side) perfused placentas as previously done in our laboratories (adapted after (Schneider and Huch 1985)). No significant differences in glucose consumption, lactate production, secretion of $\beta$-hCG or consumption of oxygen was detected.

Two cotyledons from each placenta were cut out surrounded by sufficient tissue for fixation in the chambers. On the upside, the maternal tissue was penetrated by four blunt metal cannulae through the decidual plate into the intervillous space. The fetal tissue remained untouched. The perfusion medium consisted of NCTC-135 tissue culture medium (Cambrex, Verviers, Belgium) diluted 2:1 with Earl's-Buffer (Biochrom, Berlin, Germany), and supplemented with bovine serum albumin (40 g/l; MP Biomedicals, Illkirch, France), D-glucose (1,33 g/l; Merck, Darmstadt, Germany), 
amoxillin (250 mg/l; Sigma-Aldrich), heparin (500 $\mu \mathrm{l} / \mathrm{l}$, equivalent to $2500 \mathrm{IU} / \mathrm{l}$,

Ratiopharm, Ulm, Germany) and dextran FP40 (10 g/l, Serva, Heidelberg, Germany), adjusted to an $\mathrm{pH}$ of 7,4 by $\mathrm{NaOH}$ (Roth, Karlsruhe, Germany). For perfusion, the medium was warmed up to $37^{\circ} \mathrm{C}$ and oxygenated by using a Silox-S oxygenator (Mera Senko Medical Instrument, Tokyo, Japan). The flow rate was $2.2 \mathrm{ml} / \mathrm{min}$ during the entire perfusion period. The experimental cotyledon was perfused with pure perfusion medium for $1 \mathrm{~h}$ followed by medium containing $4 \mu \mathrm{g} / \mathrm{ml}$ Mal d 1 (similar concentrations are able to induce strong basophil activation (Erdmann et al. 2005)) or $0.1 \mathrm{mg} / \mathrm{ml}$ compound 48/80 (Sigma-Aldrich) for further 4 to $5 \mathrm{~h}$. Alternatively, after $1 \mathrm{~h}$ of mock perfusion, compound $48 / 80$ has been applied as a bolus of $30 \mathrm{mg} / 5 \mathrm{ml}$ directly via the influx tubes into the placenta. The control cotyledon was perfused with pure perfusion medium up to 6 hours. To monitor the metabolic state, $\mathrm{pH}, \mathrm{pO}_{2}$ und $\mathrm{pCO}_{2}$ were analysed every 30 minutes in arterial and venous flow. Venous outflow from both cotyledons was collected in 10 minutes steps for further analysis. To remove remaining tissue fragments, samples were centrifuged for $10 \mathrm{~min}$, at $3500 \mathrm{~g}$ and $4^{\circ} \mathrm{C}$. Supernatants were stored in aliquots at $-20^{\circ} \mathrm{C}$ until analysis.

\section{Spectrophoto-fluorometrically quantification of histamine}

The histamine concentration in the perfusion outflow from the experimental and the control cotyledon of 2 placentas stimulated with compound $48 / 80$ and 2 placentas stimulated with Mal d 1 was measured spectrophoto-fluorometrically as described in detail elsewhere (Shore et al. 1959, Ronnberg and Hakanson 1984). The extraction protocol and the excitation wave lengths were adapted to the analysis of perfusion medium. Histamine was extracted from $0.5 \mathrm{ml}$ perfusion medium by using a mixture of $0.5 \mathrm{ml} 0.9 \% \mathrm{NaCl}$ (Roth), $2.5 \mathrm{ml} \mathrm{n}$-butanol (Roth) and $0.2 \mathrm{ml} 3 \mathrm{M} \mathrm{NaOH}$. After 3 
$228 \mathrm{~min}$ incubation on a shaker, the mixture was centrifuged at $900 \mathrm{~g}$ for $20 \mathrm{~min}$. Two $\mathrm{ml}$ of the butanol-phase was removed and mixed with $1.2 \mathrm{ml} 0.12 \mathrm{M} \mathrm{HCl}$ and $3.8 \mathrm{ml} \mathrm{n}$ heptan (Roth). After 1 min incubation on a shaker, followed by a centrifugation at 600 $\mathrm{g}$ for $5 \mathrm{~min}$, the $\mathrm{n}$-heptan-phase was removed, cooled on ice, and mixed with $0.4 \mathrm{ml}$ $0.75 \mathrm{M} \mathrm{NaOH}$ (Roth) and $0.12 \mathrm{ml}$ methanolic o-phthalaldehyde (OPT; SigmaAldrich). After $4 \mathrm{~min}$ incubation, the reaction was terminated by addition of $0.2 \mathrm{ml} 2 \mathrm{M}$ $\mathrm{H}_{3} \mathrm{PO}_{4}$ on ice. The fluorescence was measured at $\lambda \mathrm{Ex}=355 \mathrm{~nm} ; \lambda \mathrm{Em}=440 \mathrm{~nm}$ using the Fluorescenence HPLC Monitor RF_551 (Shimadzu, Duisburg, Germany) with $40 \% \mathrm{MeOH} /$ aqua dest. as eluent. The fluorescence data were acquired and calculated using Chromeleon-software (Dionex, Germering, Germany). The standard curve was done in duplicates and ranged from 0.5 to $50 \mathrm{ng} / \mathrm{ml}$ (dilution steps: 0; 0.5; $1 ; 3 ; 5 ; 10 ; 20 ; 50 \mathrm{ng} / \mathrm{ml} ; \mathrm{R}^{2}>0.998$ ) and revealed a lower detection limit of $5 \mathrm{ng} / \mathrm{ml}$. The coefficient of variance (CV) was below $1.5 \%$.

\section{Quantification of IL-2, IL-4, IL-6, IL-10, TNF and IFN- $y$ using a cytometric multiplex bead array}

The cytokines IL-2, IL-4, IL-6, IL-10, TNF and IFN- $y$ were measured in the conditioned perfusion medium by using a cytometric multiplex bead array following the manufacturer's kit instructions (Human Th1/Th2 Cytokine Kit II, BD Bioscience, Heidelberg, Germany).

Briefly, the samples (perfusion medium or standard) were mixed (1:1:1) with antibody-coated fluorescent beads $(\lambda \mathrm{Em}=670 \mathrm{~nm})$ and the R-phycoerythrin conjugated detection antibodies $(\lambda E m=575 n m)$, and incubated shaking for 3 hours at room temperature in the dark. For standard, recombinant proteins (IL-2, IL-4, IL-6, IL10, TNF and IFN- $\gamma$; from assay kit) were dissolved in buffer medium and serially 
diluted (1:1) from 5000 to $20 \mathrm{pg} / \mathrm{ml}$ for each cytokine. The beads were washed, spinned down (200 g, $5 \mathrm{~min}$ ), and after removement of supernatants, measured on a flow cytometer (FACS Calibur; BD Bioscience) by using the implemented FCAP Array v1 0.1 . kit software with 5-parametric-curve fitting. The sensitivity limits were $2.6 \mathrm{pg} / \mathrm{ml}$ for IL-2, $2.6 \mathrm{pg} / \mathrm{ml}$ for IL-4, $3 \mathrm{pg} / \mathrm{ml}$ for IL-6, $2.8 \mathrm{pg} / \mathrm{ml}$ for IL-10, $2.8 \mathrm{pg} / \mathrm{ml}$ for TNF and $7.1 \mathrm{pg} / \mathrm{ml}$ for IFN-y. The CV was below $10 \%$.

\section{Determination of CXCL10, CXCL11, CCL17, CCL22 and IL-13 by an in-house multiplex Luminex assay}

The levels of CXCL10, CXCL11, CCL17, CCL22 and IL-13 in the perfusion medium were measured using an in-house multiplex Luminex assay, as described in detail elsewhere (Abrahamsson et al. 2011). Briefly, the monoclonal anti-human CXCL10 (clone 4D5, BD Biosciences, Stockholm, Sweden), CXCL11 (clone 87328, R\&D Systems, Abingdon, UK), CCL17 (clone 54026, R\&D Systems), CCL22 (clone 57226, R\&D Systems) and IL-13 (Ref: M191302, Sanquin, Amsterdam, The Netherlands) antibodies were covalently coupled to carboxylated microspheres at a concentration of $5 \mathrm{\mu g}$ antibody $/ 10^{6}$ microspheres, using the protocol recommended by the manufacturer (Luminex Corporation, Austin, TX, USA). 2000 coupled microspheres were added to each well of a $1.2 \mu \mathrm{m}$ pore-size filter plate (Millipore multiscreen, Millipore Corporation, Bedford, USA) and incubated over night with either recombinant human CXCL10, CXCL11, CCL17, CCL22 and IL-13 (R\&D Systems), or samples diluted 1:2. The microspheres were washed, incubated for $1 \mathrm{~h}$ with biotinylated anti-human CXCL10 (1000 ng/ml, clone 6D4, BD Biosciences), CXCL11 (500 ng/ml, BAF320, R\&D Systems), CCL17 (500 ng/ml, BAF364, R\&D Systems), CCL22 (200 ng/ml, BAF336, R\&D Systems) and IL-13 (200 ng/ml, Ref: M191304, 
Sanquin) antibody, followed by incubation with $1 \mu \mathrm{g} / \mathrm{ml}$ Streptavidin R-phycoerythrin conjugate (Molecular Probes, Eugene, USA) for 30 minutes. A Luminex ${ }^{100}$ instrument

(Biosource, Nivelles, Belgium) was used for analysis of the samples and the data acquisition was performed using the StarStation 2.3 software (Applied cytometry systems, Sheffield, UK) with 5-parametric-curve fitting. The sensitivity limits were 6 $\mathrm{pg} / \mathrm{ml}$ for CXCL10 and CXCL11, $1 \mathrm{pg} / \mathrm{ml}$ for CCL17 and CCL22 and $8 \mathrm{pg} / \mathrm{ml}$ for IL-13. 284 The samples were analyzed in duplicates and the CV was below $15 \%$. Undetectable 285 levels were given the value of the half cut-off.

\section{Statistical analysis}

Due to the explorative nature of the study and the small sample size the data were primarily analyzed by descriptive methods. To generate hypotheses about the response to allergen exposure over time mixed linear models were applied with time, allergen and their interaction as fixed and subject as random factors. The level of significance was 0.05 . The analyses were performed with SAS 9.3 software. 


\section{Results}

Generally, in most cases the analytes in the perfusate decrease during the first hour of placenta perfusion. The values at timepoint 0 represent the concentrations at the very beginning of perfusion and may be similar to serum concentrations. The first hour of perfusion is performed with pure medium without a stimulus, which usually reduces the concentrations.

\section{Compound 48/80 induced histamine and chemokine release}

303 To determine if mast cells in the placenta are able to degranulate, two placentas from 304 non-allergic mothers were perfused with compound $48 / 80$. When this was added as a 305 bolus to the placenta 60 minutes after the beginning of perfusion, a strong histamine 306 release was immediately detectable (Fig 1). After this rapid response to compound $30748 / 80$, the histamine levels decreased to basis level, followed by a second increase 308 of histamine release after 3 hours, albeit no further compound $48 / 80$ was added. 309 The chemokines CXCL10, CXCL11, CCL17 and CCL22 (Fig 2A-D) were also 310 released rapidly after mast cell activation with compound 48/80, but not IL-6 (Fig 2E) 311 and TNF (Fig 2F).

When $0.1 \mathrm{mg} / \mathrm{ml}$ compound $48 / 80$ was permanently added to the perfusion medium, 314 histamine levels were very low and only sporadically detectable during the analysed 315 time period. In analogy to the bolus application, at the initiation of perfusion with 316 compound 48/80, a rapid release of the chemokines CXCL10, CXCL11, CCL17 and 317 CCL22, but not of the cytokines IL-2, IL-4, IL-13, IFN- $\gamma$, IL- 6 and TNF was observed 318 (data not shown). 


\section{Allergen induced cytokine and chemokine release}

321 The activity and stability of the apple allergen preparation has been demonstrated 322 previously by performing series of analyses including SDS-PAGE, two-dimensional 323 electrophoresis, immunoblotting, RAST inhibition, and prick test (Rudeschko et al. 324 1995a, Rudeschko et al. 1995b). Perfusion of placentas with apple allergen induced 325 a time-dependent increase of IL-6 (Fig 3A) and TNF (Fig 3B) as compared to the 326 unstimulated cotyledon, in placentas of women with apple allergy. The stronger 327 increase after stimulation could be confirmed by a significant interaction between 328 time and allergen for TNF $\left(F_{(1,125)}=16.6, p<0.001\right)$ and IL-6 $\left(F_{(1,116)}=25.1, p<0.001\right)$ in 329 the mixed model analyses. IL-6 and TNF were also released spontaneously from 330 placentas of non-allergic women, but without further increase after instillation of apple 331 allergen. The CCL17 levels were slightly elevated after allergen stimulation in 332 placentas of women without apple allergy (Fig 3C), but the effect was not statistically 333 significant (detailed results in supplementary table 1). The secreted levels of 334 CXCL10, CXCL11 and CCL22 from the experimental and control cotyledon were 335 similar in both groups (data not shown), and the levels of IL-2, IL-4, IL-13 and IFN- $\gamma$ 336 were undetectable or only sporadically detectable in the samples. Histamine release 337 was not induced by stimulation with apple allergen (all results summarized in table 1). 


\section{Discussion}

This study has been performed to test if in patients with an oral allergy syndrome, allergen challenge of the placenta induces release of histamine, cytokines or chemokines. As a positive control for the potential of placental mast cell reactivity, placentas have been perfused with compound $48 / 80$. This degranulating stimulus induced histamine secretion, but no detectable effects on the analysed cytokines. On the other hand, apple allergen challenge induced secretion of IL-6 and TNF in placentas from allergic mothers. Therefore, in our system the source of both cytokines seems to be distinct from mast cells, although previous studies have demonstrated that mast cells can release TNF and IL-6 selectively upon stimulation with compound 48/80, PMA or several other stimuli even without simultaneous histamine release (Kruger-Krasagakes et al. 1999, Gibbs et al. 2001, KandereGrzybowska et al. 2003, Theoharides and Kalogeromitros 2006, Kim et al. 2007, Kulka et al. 2008), thus making it inappropriate to completely exclude the ability of mast cells in the placenta to produce these cytokines.

355 It may be argued that the way of delivery, with or without labor, influences cytokine 356 levels as reported for IL-6, but not TNF in cord blood (Duncombe et al. 2010). The 357 intraindividual control perfusion, one cotyledon with and one without allergen, should overcome these discrepancies in basic levels. Levels of both cytokines increase during the course of placenta perfusion and can be seen as stress markers, which have been reported in previous studies (Pierce et al. 2002, Di Santo et al. 2007). We observed this increase in both groups of allergic and healthy individuals, but the further increase of these two proinflammatory cytokines in response to apple allergen in placentas of allergic mothers indicates an enhanced general inflammatory activity 364 in this group. Inhalant allergens have been shown to induce IL-6 and TNF production 
in airway epithelial cells (Vroling et al. 2007), alveolar macrophages (Chen et al. 2003), monocytes and monocyte-derived macrophages (Andersson Lundell et al. 2005), indicating that allergens are able to evoke proinflammatory immune responses as an early response to the allergen. The allergen induced IL-6 and TNF levels from monocytes were independent of LPS contamination, evaluated by adding the LPSneutralizing agent polymyxin B (Andersson Lundell et al. 2005). Placenta perfusion systems are not sterile and although all parts of the system (e.g. tubing) are intensively cleaned and disinfected after each use, potential endotoxin contamination cannot be excluded. Nevertheless, the different responses on allergens (from the same batches) in allergic and non-allergic women, when comparing the allergen perfused and control cotyledons, suggest that the induction of IL-6 and TNF are in response to the allergen rather than to endotoxins.

Even though IL-6 and TNF are not generally considered as strong inducers of Th2associated immune responses, house dust mite stimulated alveolar macrophages from mice promote T cell proliferation and Th2-cell development by up-regulation of costimulatory B7 molecules and secretion of IL-6 and TNF, indicating a possible role for these proinflammatory cytokines in the allergic inflammation (Chen et al. 2003). Maternal allergy did not correlate with elevated Th2-like chemokine responses to apple allergen in our model, but a diminutive allergen induced increase of CCL17 levels was observed in placentas of non-allergic women. These findings do not necessary exclude the possibility of enhanced Th2-like responses to allergens in the placentas of allergic women, as the signature cytokines of a Th2-like immunity, IL-4 and IL-13, were undetectable in the majority of the samples. Thus, low levels of these Th2-like cytokines might be induced, but, due to methodological limitations, 389 impossible to detect. CCL17 and CCL22 are readily detectable in the human 
circulation, probably explaining the high chemokine levels in the beginning (time point 0) of the perfusion experiment (Fig 3A-D). Only approximately $50 \%$ of the samples had detectable levels of CCL17 during the course of perfusion, which indicates that its physiological source is outside the placenta.

Mast cells contribute to the allergic inflammation by the release of granule-mediated substances such as histamine by an FcERI-dependent pathway, whereas mast cell activation by FcERI-independent pathways such as Toll like receptor signalling, stimulation with components from the complement system, cytokines and chemokines, may be implicated in various innate and adaptive immune responses (Metcalfe et al. 1997, Menzies et al. 2011). The present study demonstrates the kinetics of histamine expression from placental mast cells on specific activation by compound 48/80, which indicates their potential for classical allergen-induced inflammatory reactions. A previous study has indirectly reported histamine release from placental mast cells by demonstrating a decrease of histamine in placenta tissue after 90 minutes perfusion with atrial natriuretic peptide (Szukiewicz et al. 2001). Degranulation of placental mast cells has also been described after stress induced substance $P$ increase in murine placentas (Markert et al. 1997). Isolated uterine mast cells secrete histamine through the FcERI-dependent pathway in response to anti-IgE stimulation (Massey et al. 1991). IgE is present in the human placenta: in the maternal as well as in the fetal tissue in women with, but also without, allergies (Rindsjo et al. 2010).The placenta IgE levels correlate with those in blood (Joerink et al. 2009). Therefore, we did not reproduce these experiments, as all 412 patients in our analysis had $\lg E$ to Mal $d 1$ and Bet $v 1$ in their serum. Histamine is 413 an important mediator in the course of pregnancy, in particular during labour by 414 inducing contractions of the myometrium, both directly and indirectly by inducing 
prostaglandin production, indicating that mast cell degranulation in the reproductive

tract needs to be strictly regulated (reviewed in (Menzies et al. 2011)). In the here applied placenta perfusion system, histamine release was not induced by tissue perfusion with apple allergen. It may be argued that too little bioactive apple allergen concentrations have reached the mast cells. This may be due to dilution of allergens or to filter effects of tissue barriers, but also to influences on the stability of apple allergen such as by medium or tissue components (Rudeschko et al. 1995b). As allergens may appear via the circulation in the placenta, it is tempting to speculate that presence of a high proportion of mast cells with allergen specific $\lg E$ antibodies attached to FcERI in the placenta, may confer a risk for preterm labour. Maternal allergy has been associated with longer gestational age, higher birth weight (Somoskovi et al. 2007) and less pre-term births (Savilahti et al. 2004), indicating favourable effects on the maintenance of pregnancy rather than detrimental effects, but the role of histamine in the underlying mechanisms is not known. The presence of maternal $\lg E$ in the placenta has been summarized recently. It was mainly detected around fetal Hofbauer cells in the villi, but little is known about its binding on mast cells (Rindsjo et al. 2010).

The lgE- and FceRl-independent mechanism for mast cell degranulation by compound $48 / 80$ is not determined, but an effect on the plasma membrane has been suggested, for example through interactions with different types of receptors, membrane transporters and translocation across the membrane (Ferry et al. 2002). Subsequent signalling through the $\mathrm{G}$ protein coupled receptors Mas related gene X1 (MrgX1) and MrgX2 have been suggested (Tatemoto et al. 2006, Kashem et al. 2011). We could demonstrate that mast cells in the placenta are able to synthesise and secrete chemokines upon activation, as compound 48/80 induced release of 
CXCL10, CXCL11, CCL17 and CCL22 in the present study. Cytokines and

chemokines are in general considered to be de novo synthesised upon mast cell

activation (Kalesnikoff and Galli 2008, Menzies et al. 2011). On the other hand, mast

cells and basophils can release preformed, as well as newly synthesised, TNF (Gordon and Galli 1991, Gibbs et al. 2001, Kulka et al. 2008), IL-4 (Gibbs et al. 1996), IL-6 (Kruger-Krasagakes et al. 1999, McCall-Culbreath et al. 2011) and CXCL8 (Gibbs et al. 2001) following activation. The chemokines CXCL10, CCL17, CXCL11 and CCL22 were released rapidly, only 20 minutes after addition of compound $48 / 80$. The latter two remained steadily secreted during the entire perfusion experiment (Fig 3B and 3D), whereas after approximately $3 \mathrm{~h}$, the concentrations of CXCL10 (Fig 3A) and CCL17 (Fig 3C) have decreased to levels similar to the control cotyledon. Thus, our data possibly indicate a rapid release of preformed chemokines, followed by a continuous release of newly synthesized CXCL11 and CCL22.

In conclusion, allergen induced mast cell degranulation, cytokine and chemokine responses may occur in the placenta. As previously summarized, these reactions can shape or prime infant immune development. The increased allergen induced IL-6 and TNF levels in placentas of allergic women as compared to non-allergic women, indicate enhanced proinflammatory immune responses to apple allergen in the allergic group, potentially influencing the shaping of immune responses in the offspring. This observation may contribute to explain the elevated risk of newborns from allergic mothers under allergen exposure for developing allergies in later life. 


\section{Acknowledgements}

464 The placenta perfusion experiments were supported by the Institut Danone (Haar, Germany). During the experimental phase of this study, the Placenta Lab, Jena, was a member of "EMBIC" (Embryo Implantation Control; www.embic.org), an European Network of Excellence within the $6^{\text {th }}$ Framework Programme of the European Union (contract no. 512040). We thank B. Fahlbusch, formerly Institute of Clinical Immunology, University Hospital Jena, for her great support in apple allergen preparation. We thank L. Seyfarth and J. Heinzelmann for their technical support.

471 This work was also supported by the Swedish Research Council (K2011-56X-21854472 01-06), the Cancer and Allergy Association and the Olle Engkvist Foundation to MJ.

473 The cooperation between the Swedish and German groups has been initiated thanks 474 to a travel grant to Jena for MA by the Boehringer Ingelheim Fonds (Germany).

1

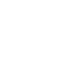

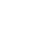

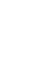

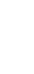

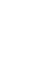


Table 1

2478

$\begin{array}{ll}3 & 479\end{array}$

5480

6

7

Table 1. A summary of the induced analytes after Compound $48 / 80$ or Mal $d 1$ stimulation.

\begin{tabular}{lccc}
\hline Analyte & $\begin{array}{c}\text { Compound 48/80 } \\
\text { Non-allergic, } \mathrm{n}=2\end{array}$ & $\begin{array}{c}\text { Mal d 1 } \\
\text { Allergic, } \mathrm{n}=4\end{array}$ & $\begin{array}{c}\text { Mal d 1 } \\
\text { Non-allergic, } \mathrm{n}=3\end{array}$ \\
\hline Histamine & + & $-(\mathrm{n}=2)$ & Not analysed \\
IL-6 & - & + & - \\
TNF & - & + & - \\
CXCL10 & + & - & - \\
CXCL11 & + & - & - \\
CCL17 & + & - & + \\
CCL22 & + & - & -
\end{tabular}

+; The production of the analyte was induced by stimulation with Compound $48 / 80$ or Mal d 1 as compared to the unstimulated cotyledon.

-; The production of the analyte was not induced by stimulation with Compound $48 / 80$ or Mal d 1 as compared to the unstimulated cotyledon. 
$488 \quad$ Figure legends

489 Figure 1. Two cotyledons of a human placenta from a non-allergic woman have been simultaneously and independently perfused for $320 \mathrm{~min}$. After $1 \mathrm{~h}, 30 \mathrm{mg}$ compound $48 / 80$ was injected into the medium of one cotyledon (grey bars), while the other was exclusively medium pefused for control (white bars). The histamine concentration has been analysed in the placenta outflow medium in 20 min steps and has been calculated as ng histamine $/ \mathrm{ml}$ perfusion medium $/ \mathrm{kg}$ placenta tissue.

Figure 2. Two cotyledons of a human placenta from a non-allergic woman have been simultaneously and independently perfused for $320 \mathrm{~min}$. After $1 \mathrm{~h}, 30 \mathrm{mg}$ compound $48 / 80$ was injected into the medium of one cotyledon (permanent line), while the other was exclusively medium pefused for control (broken line). Chemokine (A:

CXCL10; B: CXCL11; C: CCL17; D: CCL22) and cytokine (E: IL-6; F:TNF) concentrations have been quantified by cytometric bead arrays in the placenta outflow medium at several time points (dots) and calculated as pg chemokine or cytokine $/ \mathrm{ml}$ perfusion medium $/ \mathrm{kg}$ placenta tissue.

Figure 3. Two cotyledons of human placentas from women with and without apple allergy have been simultaneously and independently perfused for up to $360 \mathrm{~min}$. Beginning after $1 \mathrm{~h}$, one cotyledon was perfused with medium containing $4 \mu \mathrm{g} / \mathrm{ml} \mathrm{Mal}$ d 1 apple allergen (permanent line), while the other was exclusively medium pefused for control (broken line). IL-6, TNF and CCL17 concentrations have been quantified by cytometric bead arrays in the placenta outflow medium at several time points (dots) and calculated as $\mathrm{pg} / \mathrm{ml}$ perfusion medium $/ \mathrm{kg}$ placenta tissue. The

512 spontaneous secretion of these factors during the course of perfusion has been 
513 reported previously and can be seen as the individual baseline for each placenta (Di 1 2514 Santo et al. 2007). For visual clarity only medians are presented (for detailed data 


\section{References}

Abrahamsson, T.R., et al., 2011. A th1/th2-associated chemokine imbalance during infancy in children developing eczema, wheeze and sensitization. Clin Exp Allergy. 41, 1729-39

Andersson Lundell, A.C., et al., 2005. Cat allergen induces proinflammatory responses by human monocyte-derived macrophages but not by dendritic cells. Allergy. 60, 1184-91

Andrew, D.P., et al., 1998. Stcp-1 (mdc) cc chemokine acts specifically on chronically activated th2 lymphocytes and is produced by monocytes on stimulation with th2 cytokines il-4 and il-13. J Immunol. 161, 5027-38

Asher, M.I., et al., 2006. Worldwide time trends in the prevalence of symptoms of asthma, allergic rhinoconjunctivitis, and eczema in childhood: Isaac phases one and three repeat multicountry cross-sectional surveys. Lancet. 368, 73343

Barker, D.J., et al., 1989. The intrauterine and early postnatal origins of cardiovascular disease and chronic bronchitis. J Epidemiol Community Health. $43,237-40$

Burr, M.L., et al., 1989. Changes in asthma prevalence: Two surveys 15 years apart. Arch Dis Child. 64, 1452-6

Chen, C.L., et al., 2003. House dust mite dermatophagoides farinae augments proinflammatory mediator productions and accessory function of alveolar macrophages: Implications for allergic sensitization and inflammation. J Immunol. 170, 528-36

Cole, K.E., et al., 1998. Interferon-inducible t cell alpha chemoattractant (i-tac): A novel non-elr cxc chemokine with potent activity on activated $t$ cells through selective high affinity binding to cxcr3. J Exp Med. 187, 2009-21

Di Santo, S., et al., 2007. Dual in vitro perfusion of an isolated cotyledon as a model to study the implication of changes in the third trimester placenta on preeclampsia. Placenta. 28 Suppl A, S23-32

Douwes, J., et al., 2008. Farm exposure in utero may protect against asthma, hay fever and eczema. Eur Respir J. 32, 603-11 
Duncombe, G., et al., 2010. II-6 and tnfalpha across the umbilical circulation in term pregnancies: Relationship with labour events. Early human development. 86, 113-7

Edelbauer, M., et al., 2004. Maternally delivered nutritive allergens in cord blood and in placental tissue of term and preterm neonates. Clin Exp Allergy. 34, 189-93

Edelbauer, M., et al., 2003. Dose-dependent and preterm- accentuated diaplacental transport of nutritive allergens in vitro. Int Arch Allergy Immunol. 130, 25-32

Ege, M.J., et al., 2006. Prenatal farm exposure is related to the expression of receptors of the innate immunity and to atopic sensitization in school-age children. J Allergy Clin Immunol. 117, 817-23

Erdmann, S.M., et al., 2005. In vitro analysis of birch-pollen-associated food allergy by use of recombinant allergens in the basophil activation test. Int Arch Allergy Immunol. 136, 230-8

Ferry, X., et al., 2002. G protein-dependent activation of mast cell by peptides and basic secretagogues. Peptides. 23, 1507-15

Gibbs, B.F., et al., 1996. Purified human peripheral blood basophils release interleukin-13 and preformed interleukin-4 following immunological activation. Eur J Immunol. 26, 2493-8

Gibbs, B.F., et al., 2001. Human skin mast cells rapidly release preformed and newly generated tnf-alpha and il-8 following stimulation with anti-ige and other secretagogues. Exp Dermatol. 10, 312-20

Gordon, J.R., Galli, S.J., 1991. Release of both preformed and newly synthesized tumor necrosis factor alpha (tnf-alpha)/cachectin by mouse mast cells stimulated via the fc epsilon ri. A mechanism for the sustained action of mast cell-derived tnf-alpha during ige-dependent biological responses. J Exp Med. $174,103-7$

Heinzelmann, J., 2005. Allergenstimulierte mediatorfreisetzung in humanen plazenten. Universitätsfrauenklinik. Universitätsklinikum Jena: Jena, pp. 141. Holloway, J.A., et al., 2000. Detection of house-dust-mite allergen in amniotic fluid and umbilical-cord blood. Lancet. 356, 1900-2

Imada, M., et al., 1995. Allergen-stimulated interleukin-4 and interferon-gamma production in primary culture: Responses of subjects with allergic rhinitis and normal controls. Immunology. 85, 373-80 
Jenmalm, M.C., Bjorksten, B., 1998. Development of the immune system in atopic children. Pediatr Allergy Immunol. 9, 5-12

Joerink, M., et al., 2009. Evidence for allergen-specific ige of maternal origin in human placenta. Allergy. 64, 905-12

Johnson, C.C., et al., 1996. Parental history of atopic disease and concentration of cord blood ige. Clin Exp Allergy. 26, 624-9

Kalesnikoff, J., Galli, S.J., 2008. New developments in mast cell biology. Nat Immunol. 9, 1215-23

Kandere-Grzybowska, K., et al., 2003. II-1 induces vesicular secretion of il-6 without degranulation from human mast cells. J Immunol. 171, 4830-6

Kashem, S.W., et al., 2011. G protein coupled receptor specificity for c3a and compound 48/80-induced degranulation in human mast cells: Roles of masrelated genes mrgx1 and mrgx2. Eur J Pharmacol. 668, 299-304

Keelan, J.A., et al., 1999. Cytokine abundance in placental tissues: Evidence of inflammatory activation in gestational membranes with term and preterm parturition. Am J Obstet Gynecol. 181, 1530-6

Kim, E.K., et al., 2007. Lithospermi radix extract inhibits histamine release and production of inflammatory cytokine in mast cells. Bioscience, biotechnology, and biochemistry. 71, 2886-92

KlingImayr, E., et al., 2009. Identification of b-cell epitopes of bet $v 1$ involved in cross-reactivity with food allergens. Allergy. 64, 647-51

Kondo, N., et al., 1998. Reduced interferon gamma production by antigen-stimulated cord blood mononuclear cells is a risk factor of allergic disorders--6-year follow-up study. Clin Exp Allergy. 28, 1340-4

Kruger-Krasagakes, S., et al., 1999. Adhesion of human mast cells to extracellular matrix provides a co-stimulatory signal for cytokine production. Immunology. 98, 253-7

Kulka, M., et al., 2008. Neuropeptides activate human mast cell degranulation and chemokine production. Immunology. 123, 398-410

Lampi, J., et al., 2011. Farming environment and prevalence of atopy at age 31: Prospective birth cohort study in finland. Clin Exp Allergy. 41, 987-93

Liu, C.A., et al., 2003. Prenatal prediction of infant atopy by maternal but not paternal total ige levels. J Allergy Clin Immunol. 112, 899-904 
Loibichler, C., et al., 2002. Materno-fetal passage of nutritive and inhalant allergens across placentas of term and pre-term deliveries perfused in vitro. Clin Exp Allergy. 32, 1546-51

Luster, A.D., Ravetch, J.V., 1987. Biochemical characterization of a gamma interferon-inducible cytokine (ip-10). J Exp Med. 166, 1084-97

Markert, U.R., et al., 1997. Stress triggered abortions are associated with alterations of granulated cells into the decidua. Am J Reprod Immunol. 37, 94-100

Massey, W.A., et al., 1991. Human uterine mast cells. Isolation, purification, characterization, ultrastructure, and pharmacology. J Immunol. 147, 1621-7

Mccall-Culbreath, K.D., et al., 2011. Selective, alpha2beta1 integrin-dependent secretion of il- 6 by connective tissue mast cells. J Innate Immun. 3, 459-70

Menzies, F.M., et al., 2011. The role of mast cells and their mediators in reproduction, pregnancy and labour. Hum Reprod Update. 17, 383-96

Metcalfe, D.D., et al., 1997. Mast cells. Physiol Rev. 77, 1033-79

Nomura, T., et al., 2002. Interleukin-13 induces thymus and activation-regulated chemokine (ccl17) in human peripheral blood mononuclear cells. Cytokine. 20, 49-55

Ortolani, C., et al., 1988. The oral allergy syndrome. Annals of allergy. 61, 47-52

Pease, J.E., Williams, T.J., 2006. Chemokines and their receptors in allergic disease. J Allergy Clin Immunol. 118, 305-18; quiz 319-20

Pierce, B.T., et al., 2002. The effect of fetal acidemia on fetal-placental vascular tone and production of the inflammatory cytokines interleukin- 6 and tumor necrosis factor-alpha. American journal of obstetrics and gynecology. 187, 894-7

Pietsch, S., 2006. Auro-dex visual-ens pneumoallergen test im vergleich zum pharmacia cap-system in hinsicht auf sensitivität, spezifität und präzision. medical faculty. Friedrich Schiller University: Jena, pp. 90.

Rindsjo, E., et al., 2010. Ige in the human placenta: Why there? Allergy. 65, 554-60

Ronnberg, A.L., Hakanson, R., 1984. A simplified procedure for the fluorometric determination of histamine in rat stomach. Agents Actions. 14, 195-9

Rudeschko, O., et al., 1995a. Optimization of apple allergen preparation for in vivo and in vitro diagnostics. Allergy. 50, 262-8

Rudeschko, O., et al., 1995b. Investigation of the stability of apple allergen extracts. Allergy. 50, 575-80 
Ruiz, R.G., et al., 1992. Higher risk of infantile atopic dermatitis from maternal atopy than from paternal atopy. Clin Exp Allergy. 22, 762-6

Savilahti, E., et al., 2004. Mothers of very low birth weight infants have less atopy than mothers of full-term infants. Clin Exp Allergy. 34, 1851-4

Schneider, H., Huch, A., 1985. Dual in vitro perfusion of an isolated lobe of human placenta: Method and instrumentation. Contrib Gynecol Obstet. 13, 40-7

Shore, P.A., et al., 1959. A method for the fluorometric assay of histamine in tissues. J Pharmacol Exp Ther. 127, 182-6

Somoskovi, A., et al., 2007. Population-based case-control study of allergic rhinitis during pregnancy for birth outcomes. Eur J Obstet Gynecol Reprod Biol. 131, 21-7

Steinborn, A., et al., 1998. Identification of placental cytokine-producing cells in term and preterm labor. Obstet Gynecol. 91, 329-35

Sun, J., et al., 2007. Immunoreactivity profile of peripheral blood mononuclear cells from patients with ragweed-induced allergic rhinitis. Clin Exp Allergy. 37, 9018

Szepfalusi, Z., et al., 2006. Most of diaplacentally transferred allergen is retained in the placenta. Clin Exp Allergy. 36, 1130-7

Szukiewicz, D., et al., 2001. The dose-dependent release of histamine from placental mast cells after administration of atrial natriuretic peptide. Inflammation research : official journal of the European Histamine Research Society ... [et al.]. 50 Suppl 2, S59-60

Tatemoto, K., et al., 2006. Immunoglobulin e-independent activation of mast cell is mediated by mrg receptors. Biochem Biophys Res Commun. 349, 1322-8

Theoharides, T.C., Kalogeromitros, D., 2006. The critical role of mast cells in allergy and inflammation. Annals of the New York Academy of Sciences. 1088, 78-99

Thornton, C.A., et al., 2004. Functional maturation of cd4+cd25+ctla4+cd45ra+ $t$ regulatory cells in human neonatal t cell responses to environmental antigens/allergens. J Immunol. 173, 3084-92

Till, S., et al., 1997a. II-5 secretion by allergen-stimulated cd4+ t cells in primary culture: Relationship to expression of allergic disease. J Allergy Clin Immunol. 99, 563-9 
682 Till, S., et al., 1997b. Il-13 production by allergen-stimulated t cells is increased in allergic disease and associated with il-5 but not ifn-gamma expression. Immunology. 91, 53-7

Van Der Velden, V.H., et al., 2001. Selective development of a strong th2 cytokine profile in high-risk children who develop atopy: Risk factors and regulatory role of ifn-gamma, il-4 and il-10. Clin Exp Allergy. 31, 997-1006

Vieths, S., et al., 1994. Apple allergy: The ige-binding potency of apple strains is related to the occurrence of the 18-kda allergen. Allergy. 49, 262-71

Vroling, A.B., et al., 2007. Allergen induced gene expression of airway epithelial cells shows a possible role for tnf-alpha. Allergy. 62, 1310-9 


\begin{tabular}{|c|c|c|c|c|c|c|c|c|c|c|c|c|c|c|c|c|c|c|}
\hline Analyte & $\begin{array}{c}0 \\
\text { Min }\end{array}$ & 30 & 60 & 80 & 100 & 120 & 140 & 160 & 180 & 200 & 220 & 240 & 260 & 280 & 300 & 320 & 340 & 360 \\
\hline TNF & 192 & 50 & 81 & 53 & 94 & 141 & 215 & 326 & 467 & 581 & 745 & 918 & 771 & 1068 & 1278 & 1728 & 3496 & 1921 \\
\hline \multirow{2}{*}{$\mathrm{A},+\mathrm{Al}$} & 38 & 0 & 30 & 45 & 65 & 108 & 186 & 132 & 203 & 397 & 278 & 315 & 206 & 349 & 540 & 311 & 550 & 1921 \\
\hline & 269 & 291 & 248 & 392 & 306 & 537 & 756 & 1995 & 1722 & 766 & 5537 & 4731 & 5999 & 5688 & 5873 & 8213 & 6955 & 1921 \\
\hline TNF & 80 & 124 & 119 & 117 & 114 & 126 & 134 & 102 & 103 & 169 & 231 & 436 & 250 & 317 & 409 & 450 & 479 & 342 \\
\hline \multirow[t]{2}{*}{$\mathrm{A},-\mathrm{Al}$} & 19 & 55 & 58 & 40 & 80 & 47 & 56 & 86 & 68 & 118 & 155 & 156 & 120 & 182 & 157 & 149 & 132 & 185 \\
\hline & 391 & 258 & 345 & 387 & 336 & 258 & 391 & 267 & 623 & 543 & 345 & 1123 & 3384 & 2111 & 3001 & 3549 & 3763 & 499 \\
\hline TNF & 45 & 105 & 89 & 64 & 89 & 105 & 234 & 365 & 386 & 448 & 642 & 1068 & 1354 & 1311 & 1789 & 1825 & 2975 & 2989 \\
\hline \multirow{2}{*}{$\mathrm{NA},+\mathrm{Al}$} & 45 & 43 & 40 & 52 & 63 & 74 & 126 & 242 & 342 & 383 & 509 & 1029 & 1006 & 1311 & 738 & 1789 & 1444 & 2812 \\
\hline & 120 & 129 & 147 & 243 & 454 & 528 & 978 & 1205 & 1690 & 2350 & 2187 & 3031 & 4066 & 1311 & 4747 & 1860 & 4506 & 3165 \\
\hline TNF & 69 & 65 & 143 & 131 & 140 & 152 & 405 & 318 & 311 & 417 & 682 & 1076 & 1268 & 1568 & 1691 & 2395 & 3574 & 2898 \\
\hline \multirow{2}{*}{$\mathrm{NA},-\mathrm{Al}$} & 38 & 0 & 57 & 39 & 62 & 133 & 110 & 180 & 245 & 311 & 480 & 988 & 1112 & 1100 & 930 & 1509 & 1661 & 1469 \\
\hline & 147 & 129 & 228 & 224 & 342 & 443 & 838 & 1184 & 1480 & 1452 & 2294 & 2430 & 2648 & 1724 & 3887 & 3282 & 5486 & 4327 \\
\hline IL-6 & 1605 & 356 & 402 & 365 & 243 & 371 & 482 & 298 & 560 & 418 & 539 & 1122 & 799 & 1602 & 2831 & 4474 & 7156 & 13105 \\
\hline \multirow{2}{*}{$\mathrm{A},+\mathrm{Al}$} & 1595 & 197 & 213 & 181 & 235 & 323 & 303 & 293 & 334 & 418 & 482 & 494 & 644 & 713 & 1403 & 852 & 1310 & 3554 \\
\hline & 2182 & 625 & 617 & 665 & 436 & 662 & 484 & 487 & 968 & 418 & 951 & 4785 & 2713 & 9655 & 13219 & 22504 & 21469 & 21571 \\
\hline IL-6 & 1674 & 497 & 518 & 291 & 320 & 310 & 198 & 270 & 333 & 207 & 354 & 834 & 383 & 710 & 1026 & 1260 & 1700 & 2992 \\
\hline \multirow[t]{2}{*}{$\mathrm{A},-\mathrm{Al}$} & 1207 & 458 & 168 & 247 & 243 & 193 & 183 & 149 & 137 & 130 & 190 & 284 & 280 & 372 & 378 & 439 & 359 & 439 \\
\hline & 6236 & 536 & 884 & 848 & 364 & 880 & 213 & 288 & 1002 & 410 & 431 & 1691 & 706 & 1781 & 2982 & 4475 & 4475 & 5736 \\
\hline IL-6 & 877 & 353 & 230 & 212 & 245 & 461 & 407 & 624 & 877 & 809 & 1519 & 2824 & 4275 & 4019 & 5283 & 7053 & 7850 & 11954 \\
\hline \multirow{2}{*}{$\mathrm{NA},+\mathrm{Al}$} & 617 & 139 & 140 & 174 & 164 & 144 & 274 & 444 & 515 & 613 & 1214 & 2018 & 2170 & 3088 & 4131 & 5335 & 6318 & 9030 \\
\hline & 1865 & 628 & 619 & 713 & 777 & 637 & 1146 & 1190 & 1662 & 2350 & 2678 & 4840 & 6390 & 4950 & 9837 & 8771 & 9383 & 14878 \\
\hline IL-6 & 1455 & 580 & 435 & 400 & 376 & 609 & 440 & 560 & 553 & 807 & 1403 & 2731 & 4035 & 3917 & 4589 & 6008 & 6582 & 6777 \\
\hline \multirow{2}{*}{$\mathrm{NA},-\mathrm{Al}$} & 544 & 201 & 160 & 165 & 188 & 188 & 390 & 532 & 538 & 781 & 1073 & 1364 & 1818 & 1743 & 2018 & 3760 & 4157 & 3487 \\
\hline & 2522 & 958 & 711 & 635 & 789 & 782 & 1186 & 1623 & 2121 & 2081 & 3680 & 5777 & 5391 & 4017 & 10884 & 8255 & 9008 & 10068 \\
\hline CCL17 & 407 & - & - & 46 & - & 40 & - & 37 & - & 32 & - & 29 & - & 14 & - & 31 & 31 & 28 \\
\hline \multirow{2}{*}{$\mathrm{A},+\mathrm{Al}$} & 223 & - & - & 10 & - & 10 & - & 10 & - & 10 & - & 10 & - & 9 & - & 10 & 10 & 10 \\
\hline & 792 & - & - & 383 & - & 230 & - & 285 & - & 49 & - & 45 & - & 45 & - & 45 & 45 & 47 \\
\hline CCL17 & 273 & - & - & 37 & - & 54 & - & 49 & - & 33 & - & 13 & - & 13 & - & 13 & 13 & 9 \\
\hline \multirow[t]{2}{*}{$\mathrm{A},-\mathrm{Al}$} & 16 & - & - & 10 & - & 10 & - & 10 & - & 10 & - & 9 & - & 9 & - & 9 & 9 & 9 \\
\hline & 1493 & - & - & 288 & - & 249 & - & 230 & - & 230 & - & 57 & - & 230 & - & 57 & 57 & 10 \\
\hline CCL17 & 325 & - & - & 136 & - & 119 & - & 56 & - & 88 & - & 99 & - & 17 & - & 112 & 100 & 135 \\
\hline \multirow{2}{*}{$\mathrm{NA},+\mathrm{Al}$} & 232 & - & - & 82 & - & 17 & - & 17 & - & 17 & - & 17 & - & 14 & - & 88 & 70 & 128 \\
\hline & 951 & - & - & 203 & - & 209 & - & 200 & - & 150 & - & 118 & - & 109 & - & 136 & 130 & 143 \\
\hline CCL17 & 450 & - & - & 113 & - & 28 & - & 21 & - & 21 & - & 21 & - & 19 & - & 17 & 17 & 17 \\
\hline \multirow{2}{*}{$\mathrm{NA},-\mathrm{Al}$} & 316 & - & - & 88 & - & 21 & - & 16 & - & 16 & - & 16 & - & 16 & - & 16 & 16 & 16 \\
\hline & 782 & - & - & 232 & - & 215 & - & 128 & - & 108 & - & 88 & - & 21 & - & 19 & 19 & 19 \\
\hline
\end{tabular}




\section{Supplementary table 1.}

TNF, IL-6 and CCL17 levels secreted from placentas of allergic and non-allergic women with and without allergen stimulation.

The table shows the median (first row), minimum (second row) and maximum (third row) levels of TNF, IL-6 and CCL17 in the placenta outflow medium divided to the cotyledon size $((\mathrm{pg} / \mathrm{ml}) / \mathrm{kg})$ from placentas of allergic and non-allergic women with and without allergen stimulation.

$\mathrm{A}=$ Allergic women, $\mathrm{NA}=$ Non-allergic women, $+\mathrm{Al}=$ with allergen, $-\mathrm{Al}=$ without allergen, min=minutes 


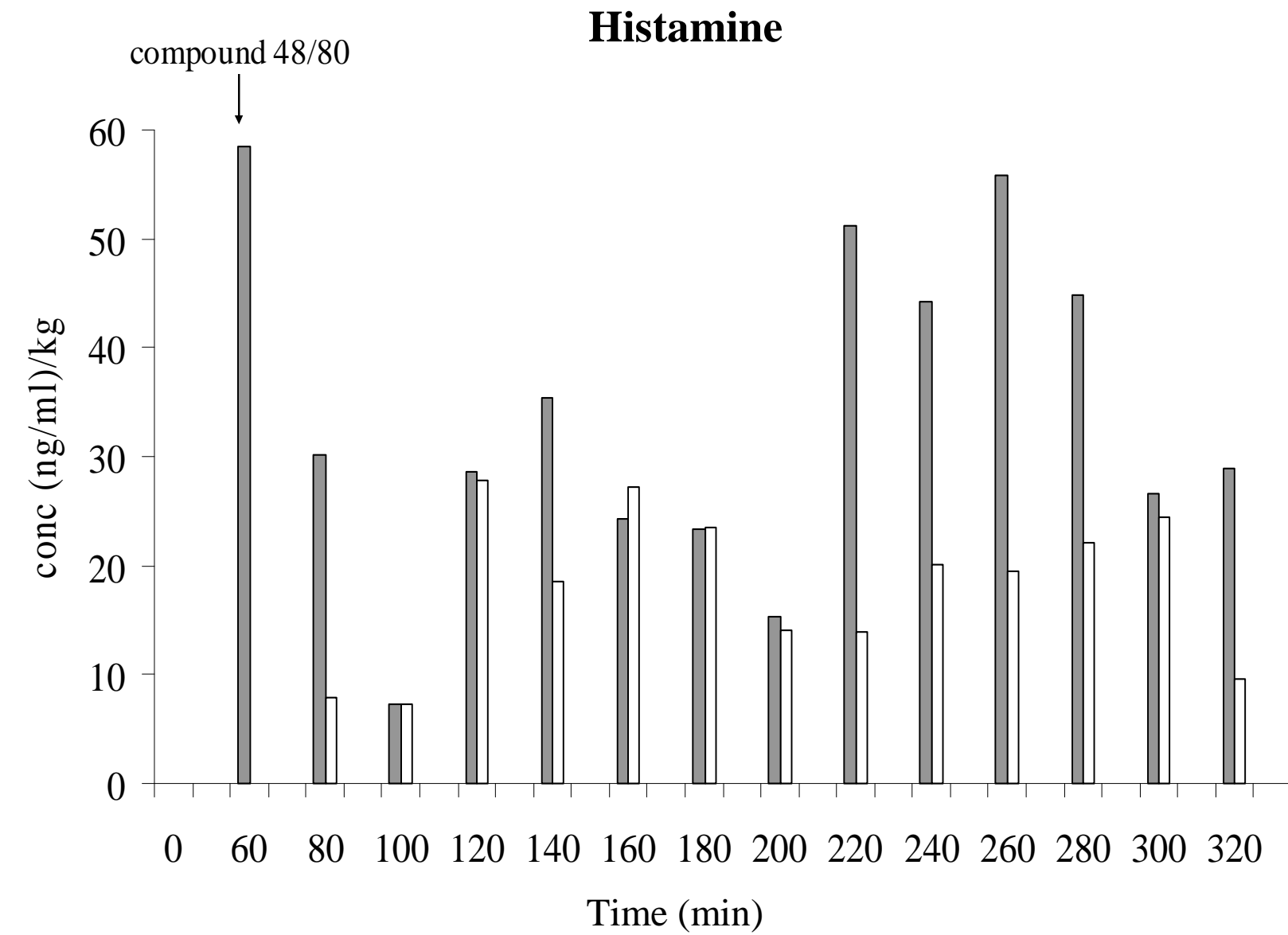

Fig 1 

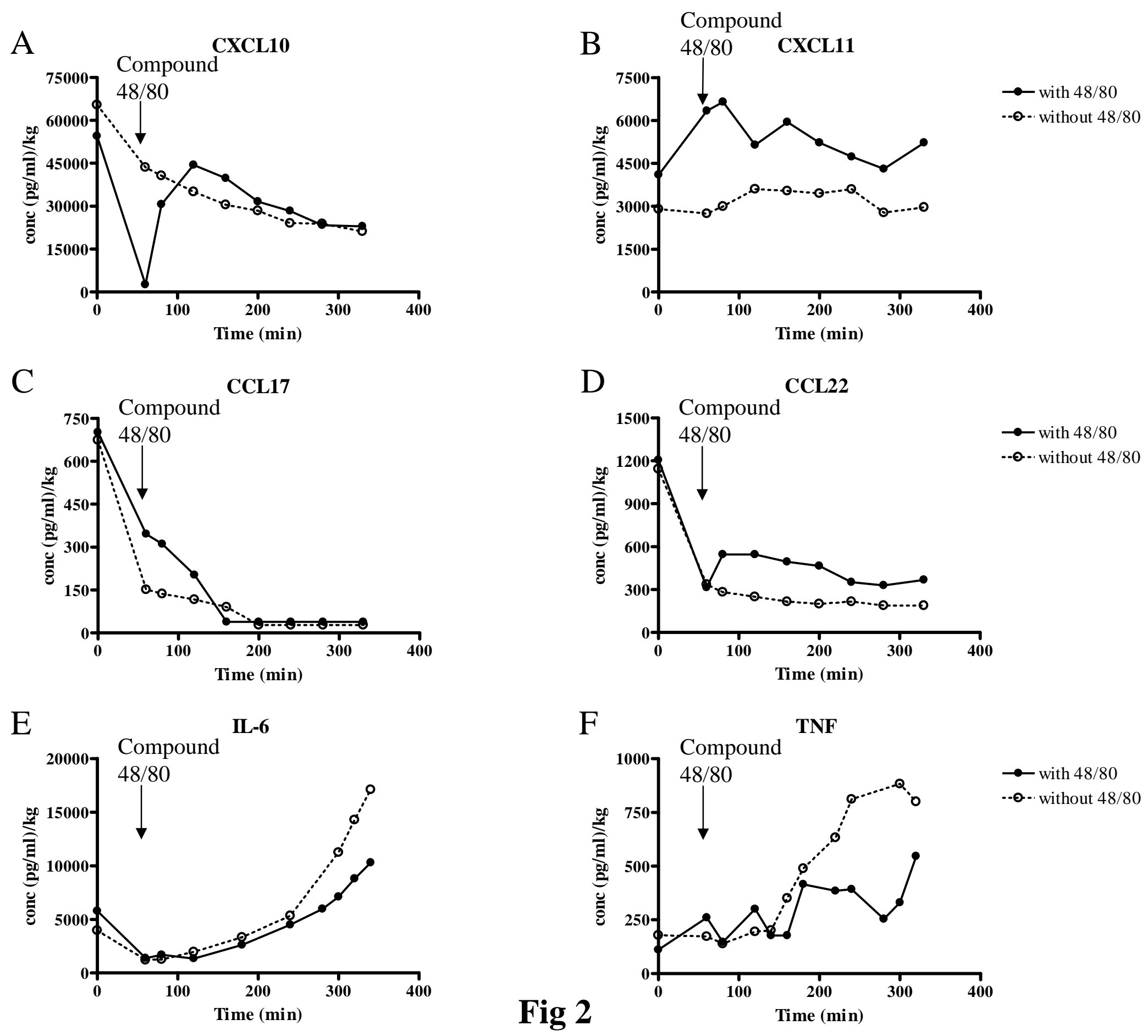
A

IL-6 in allergic women

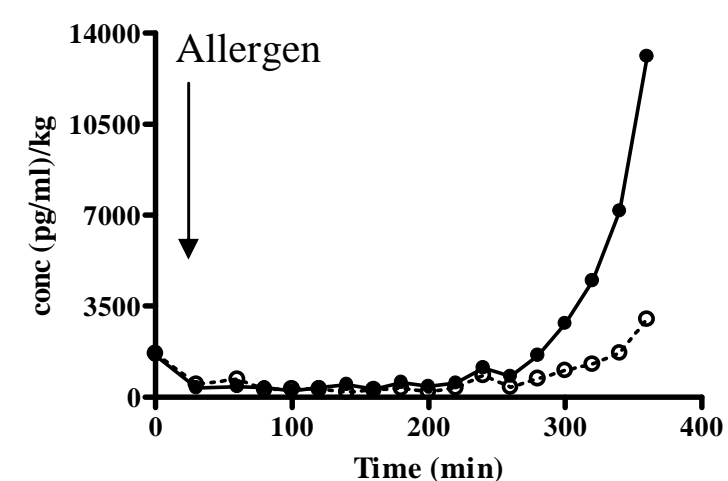

B

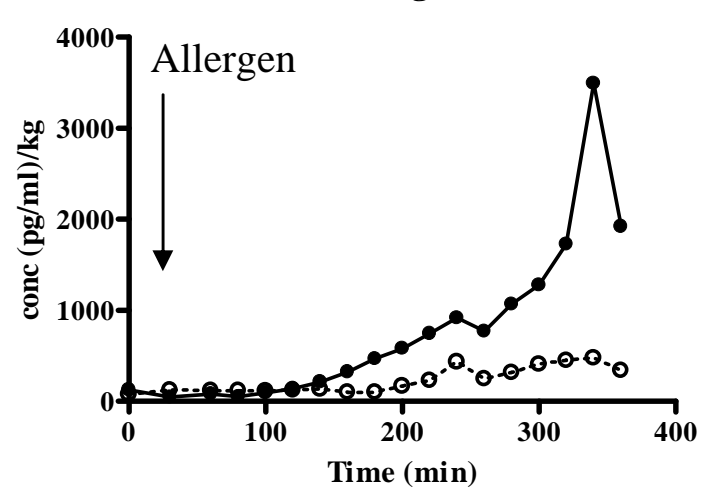

C

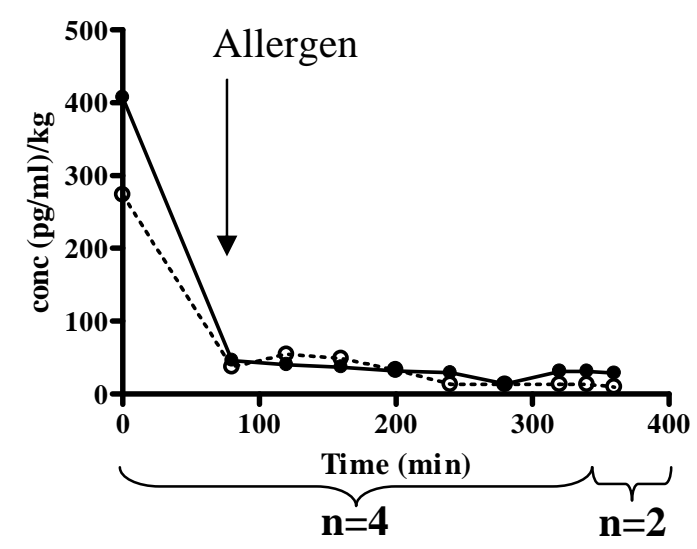

IL-6 in non-allergic women

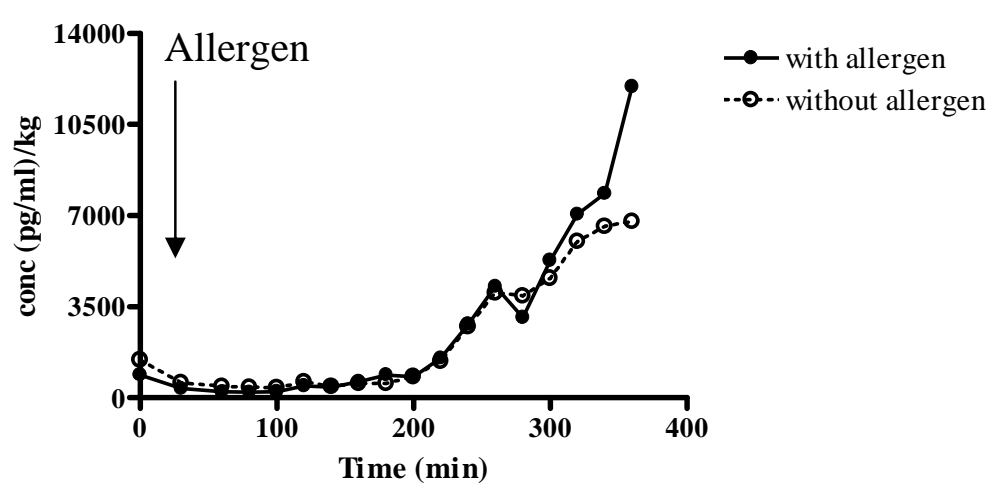

TNF in non-allergic women

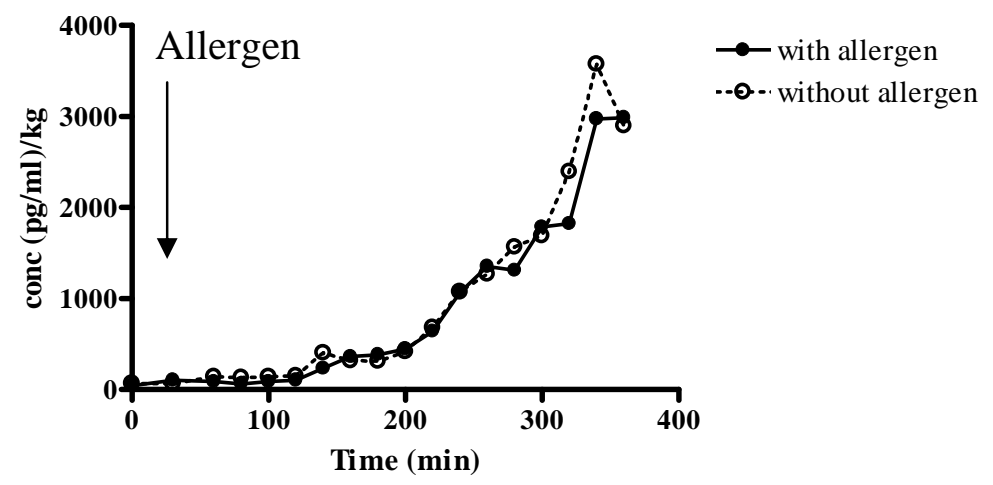

CCL17 in non-allergic women

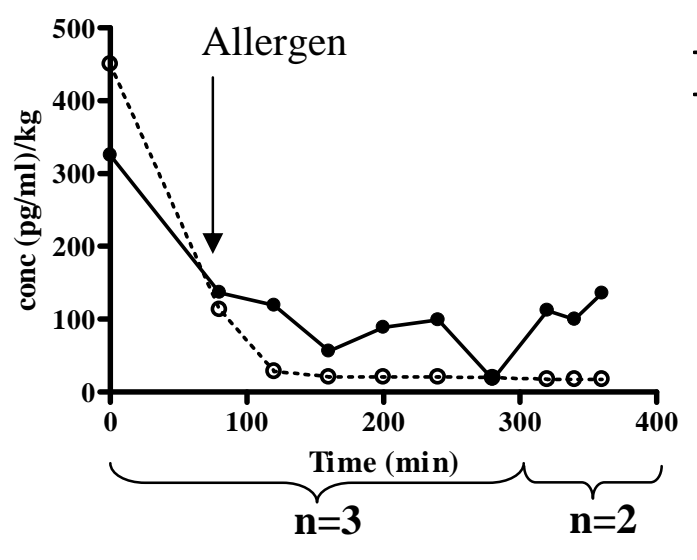

- with allergen

- - without allergen

Fig 3 